\title{
Study on Optimal Design of \\ Concrete-Filled Steel Tube Support in \\ Coal Mine
}

\author{
Liu Limin', Zhao Shijun', Cao Junzhi², Qin Zhongcheng' \\ (1.College of Mining and Safety Engineering, Shandong University of Science and \\ Technology, Qingdao, Shandong, 266590, China; \\ 2. Taian Ark Mine Science and Technology Co. Ltd, Taian, Shandong, 271026, China)
}

Abstract

This paper describes a new method of roadway support in deep mine. More than $70 \%$ of China's coal reserves exist $-800 \mathrm{~m}$ depth below. Along with the increased growing coal mining depth, mines in most mining areas are facing deep mining problems. Currently, the main support means in deep high pressure roadway are high prestressed anchored cable support and strengthen U-steel support, even many mining areas using support combined by high prestressed anchored cable and strengthen U-steel support, but that still cannot effectively control the deformation of surrounding rock in roadway. Concrete-filled steel tube support is a new type of support mode developed in recent years. In order to ensure concrete-filled steel tube support for complex pressure conditions in mine. According to the simulation results of the ANSYS software for the further optimization and improvement based on the traditional concrete-filled steel tube support. D-type concrete-filled steel tube (D-CFST) support technology is proposed. And in contrast to previous circular concrete-filled steel tube support technology in common, it can draw the conclusion that D-CFST support has prominent advantages in deep mine. This method of roadway surrounding rock control in coal mine is of great significance.

Keywords: mining engineering, roadway support, ANSYS, concrete-filled steel tube, optimal design.

\section{Introduction}

To begin with, this paper will provide a brief background on the concrete-filled steel tube. From 80 s of last century, some people carried out research work in deep roadway support. The former Soviet Union in 1983 began the thematic studies in depth more than $1600 \mathrm{~m}$ mining. In the past few years, with the increasing depth of the excavation pit in China, more and more experts and scholars paid close attention to the growing problems of excavation support in deep mine. There are many successful methods to control the surrounding rock in roadway. However, in deep mine, with a substantial increase in pressure, due to the surrounding heavy loads of the rock mass and the low strength of the coal mass, serious deformation had occurred to the roadway. Concrete-filled steel tube with high bearing capacity, corrosion resistance, ease of construction and a series of other advantages, is widely used in civil engineering ${ }^{[1-4]}$. Zang De-sheng 
had designed concrete-filled steel tube support structure, also measured the mechanical performance in laboratory and industrial test ${ }^{[5,6]}$. GAO Yan-fa proposed concrete-filled steel tube perfusion support technology in the underground, processing empty steel pipe support on the ground, then installed in the underground, which is characterized by high capacity with bearing large deformation ${ }^{[7,8]}$.

According to section forms, concrete-filled steel tube structure can be divided into circular concrete-filled steel tube structure, square concrete-filled steel tube structure, rectangular concrete-filled steel tube structure and polygons concrete-filled steel tube structure and so on. ZHANG Yao-chun had studied thin-walled steel stub columns of concrete. Research showed that restriction in circular steel tube to core concrete is better than the restriction in the square steel tube to core concrete. However the restriction in square steel tube to core concrete is the worst ${ }^{[9]}$. XIONG Jin-gang, ZHAN Mei-sen also made some related research and analysis about mechanics of thin-walled concrete-filled steel tube ${ }^{[10]}$. The following conclusions were summarized: circular steel has a better binding effect than square steel to core concrete, the actual carrying capacity compared to the nominal carrying capacity is also greatly improved, the thin-walled concrete structures which with steel hoop, when the hoop in between prior to muster or steel hoop yield that the hoop can delay local deformation of steel and limit lateral deformation of steel. SU Lin-wang, for purpose of fully evaluates the mechanical properties of concrete-filled steel tube support, using the finite element simulation software to analyze the mechanical behavior of concrete-filled steel tube [11, 12]. Discussed the axial pressure distribution of the component, bearing capacity and deformation. Also he concluded that the components internal force distribution and the dangerous section with large eccentric loading.

\section{Optimal design of concrete-filled steel tube support ${ }^{[13]}$}

\subsection{Optimization of steel tube section}

None of the methods developed is perfect in roadway support system. In order to investigate the influence of sectional shape on support properties of concrete-filled steel tube and to improve the processing performance of steel, the deformation under the action of pressure of circular steel tube is simulated by ANSYS software. Now, taken in the depth of $800 \mathrm{~m}$ to observe the specific situation of the selected node displacement for getting the ideal section shape of circular concrete-filled steel tube. The cross section of steel tube model is shown in Fig 1.

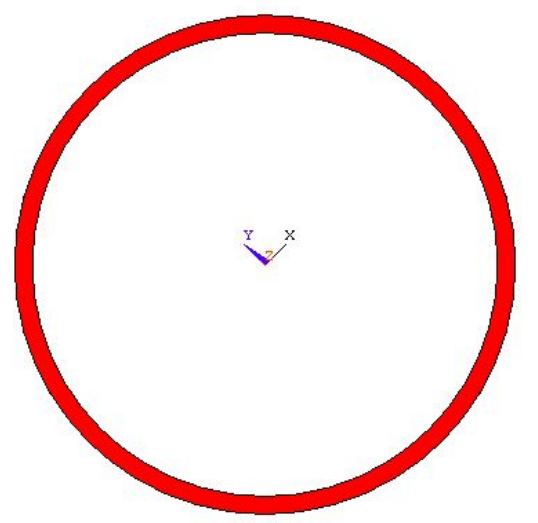

Fig.1 The model of steel tube cross section 
According to the actual size of the steel tube, analysis on the optimization of steel tube section, the steel section pressure can be simplified as plane circular pressure. The finite element model is established to full size, using plane42 element, applying a constraint load. Then solve it. The steel tube is deformed in a certain load. After solving the deformation of ring diagram as shown in Fig 2 and Fig 3.

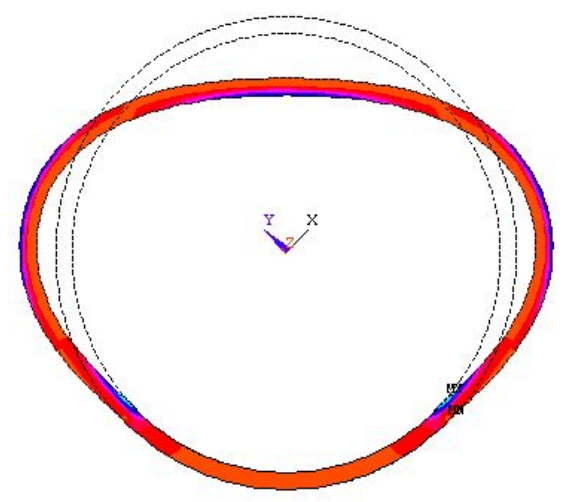

Fig.2 The maximum principal pressure state deformation of steel tube

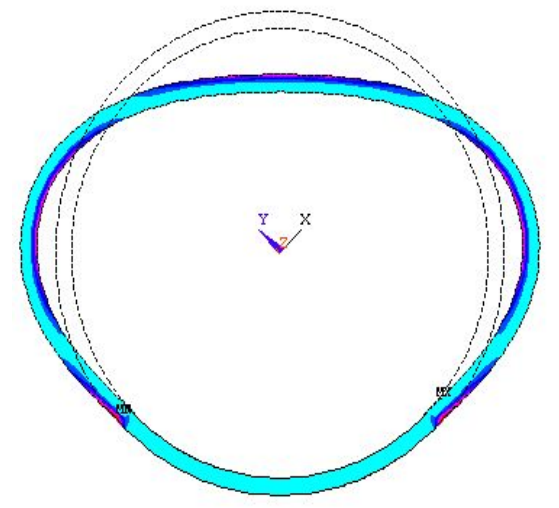

Fig.3 The minimum principal pressure state deformation of steel tube

Figure 2 and figure 3 show the maximum and minimum principal pressure form of the steel tube under loading, and get the best condition of the steel tube under pressure. The optimized type cross section of steel tube as shown in Fig 4.

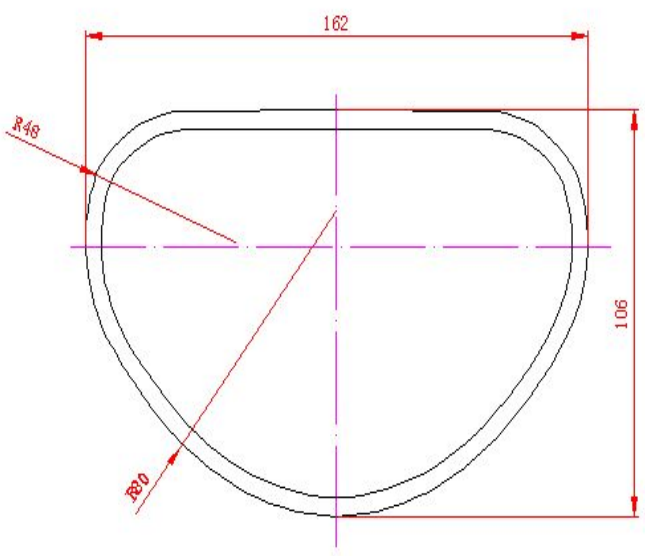

Fig.4 Cross section of D-type tube(made by $\Phi 150 \times 5$ mm steel tube) (unit: $\mathrm{mm}$ )

2.2 Optimization of concrete-filled steel tube support structure

2.2.1 Designing and model optimization According to the analysis in the previous section, the cross section shape of the circular tube under the force gradually evolved into D-type. Suppose that the whole mechanical performance of D-CFST support will be better than that of circular concrete-filled steel tube support. Now design the concrete-filled steel tube structure into a horseshoe shape, and then make a comparison from the structure to the overall mechanical properties of D-CFST support with a circular concrete-filled steel tube support, and explore that compared to the structure of the circular concrete-filled steel tube support whether the D-CFST support has obvious advantages. The cross section shape of circular, D-CFST was selected in the axial pressure analysis experiments.

Considering the different ground pressure, different geological and mining conditions to design the shape of D-CFST support. The overall dimension of the support as shown in Fig 5 . 


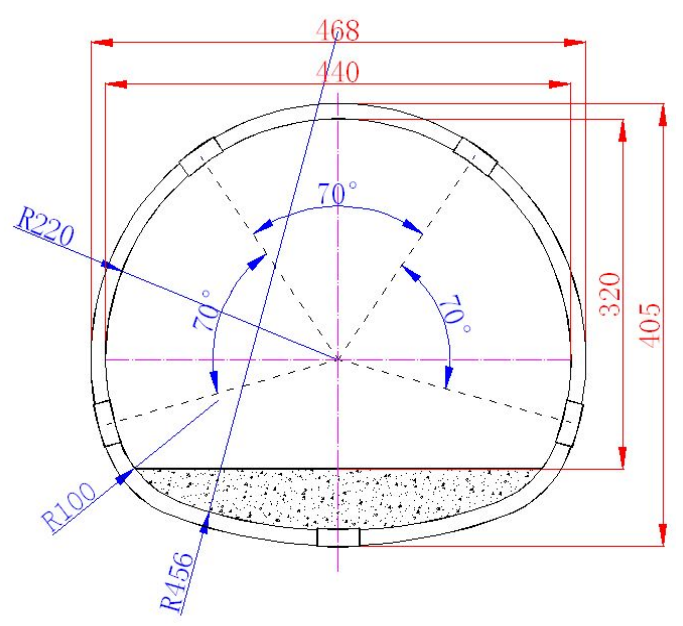

Fig.5 Dimension of D-CFST support (unit:

cm)

Supporting steel tube selection of Q235 steel tube $\Phi 150 \times 5 \mathrm{~mm}$, weight per unit length is $18.48 \mathrm{~kg} / \mathrm{m}$; Joint sleeve, $\Phi 165$ $\times 6.5 \mathrm{~mm}$ steel tube, weight per unit length is $26.43 \mathrm{~kg} / \mathrm{m}$. Concrete-filled steel tube support structure is divided into four sections: the top two segments of the support have same length; connection length with two joints of casing (center line) are $500 \mathrm{~mm}$. Choose C60 plain concrete, for the convenience of grouting to ensure the easy flow of slurry, grouting hole arranged on the pipe top, grouting hole grouting hole mouth, grouting hole mouth tube inserted inside a steel support, and it's made of $89 \times 6$ steel pipe, closed after grouting holes. Vent, a total of four, and the diameter is $12.5 \mathrm{~mm}$.

\subsubsection{Comparing the different forms of concrete-filled steel tube support structure}

Assuming that the depth of roadway is $800 \mathrm{~m}$, according to the general geological conditions, the estimated pressure is about 20MPa, while adding $20 \mathrm{MPa}$ surface force to the top and sides of the support. In order to facilitate the calculation of the horseshoe shaped support and reduce the amount of computation of ANSYS simulation software. At first, analyze D-CFST support and determine the mechanical performance of D-CFST support. Secondly, analyze circular concrete-filled steel tube support and determine the mechanical performance of circular concrete-filled steel tubes support.

According to its deformation, the test results conform to the requirements of the theory. The displacement of D-CFST support is far less than that of the circular concrete-filled steel tube support. It can be concluded in contrast that the deformation of circular concrete-filled steel tube components is far greater than D-CFST components at the same time when applying same load. In the same rock pressure circumstances, the amount of displacement of D-CFST support is clearly far less than that of the circular concrete-filled steel tube support. It can be explained that carrying capacity of the D-CFST support is higher than the circular concrete-filled steel tube support. The mechanical performance of D-CFST support is much better than that of circular concrete-filled steel tube support.

\section{An engineering example}

The mining area of Pingdingshan Tian'an coal Co. Ltd is one of the most complex mining areas at home and abroad in roadway support facing the large mining depth, complicated conditions, high ground pressure,broken slack surrounding rock and a series of other problems. With the complicated underground mining conditions, roadway support becomes more and more difficult and the cost increases quickly. The pressure behavior of -320 mining level in No.10 Colliery is 
intense, The concrete layers of the return-air roadway in the -320 mining level cracked seriously, the bottom of the roadway was up seriously. A period of time after repaired the deformation of the roadway supported by U-steel is still large. The roadways need to re-repair once or twice each year and the re-repair work is difficult also has a serious influence on the coal mine production safety. From 2012 the No.10 Mine have used D-CFST support. The actual roadway effect is shown in Fig .6.

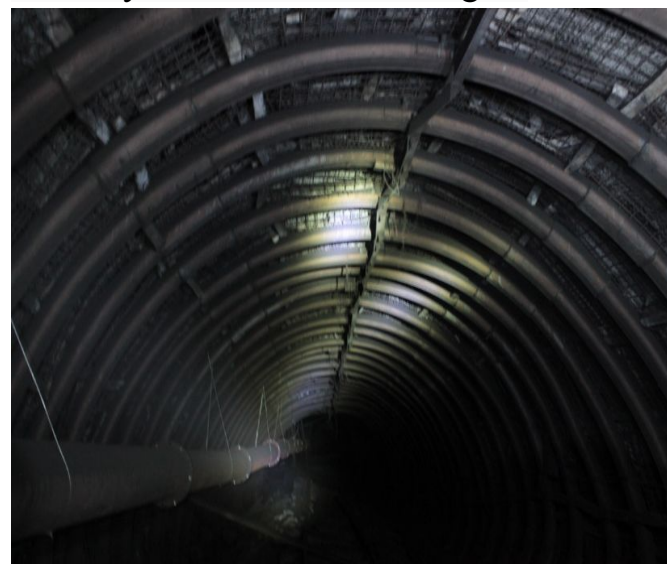

Fig.6 Supporting results of D-CFST

There are a total of 144 roadway supports and every 5 supports to set up a observation point in the $100 \mathrm{~m}$-long observation period. A total of 25 observation points have been set up. The deformation was monitored from May 6, 2013 for 120 days. Initially, the support did not play the role fully, because there is a certain gap between the concrete-filled steel tube support and the wall of roadway, and the roadway roof subsidence was obvious with fast displacement rate. A period of time later, high-strengthen support role began to emerge when the roadway surrounding rock contacted the concrete-filled steel tube support. With the gradual expansion of the contact area, the high-strengthen support role gradually increased, and the roadway surface displacement rate was significantly lower. The roadway surface deformation after initial logarithmic progress growth plateaued sharply. Due to the effects of holistic support, the deformation of roadway roof was sinking resulted in the outward expansion of the two sides of roadway. And the two sides distance of the roadway had a tendency to increase. Throughout the whole observation process, steel scaffolding intact, there was no significant damage to the support. In the 15th and 19th observation points, the rock deformation is large in the first month, the deformation between roof and floor was almost $70 \mathrm{~mm}$ and that of the roadway two sides was almost $30 \mathrm{~mm}$. The 15 th observation point distance evolution curves are shown in Fig. 7 and Fig. 8 . The 19th observation point distance evolution curves are shown in Fig.9 and Fig.10. After the surrounding rock fully contacted the support, they entered in a state of stability.

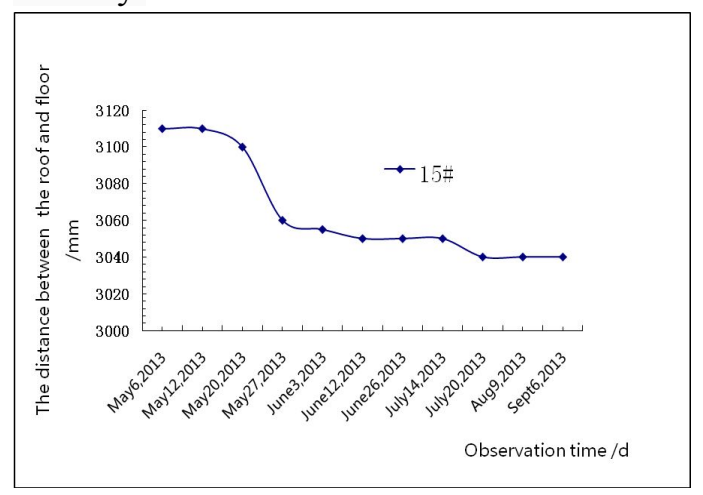

Fig.7 The evolution curve of the distance between roof and floor in the 15th observation point 


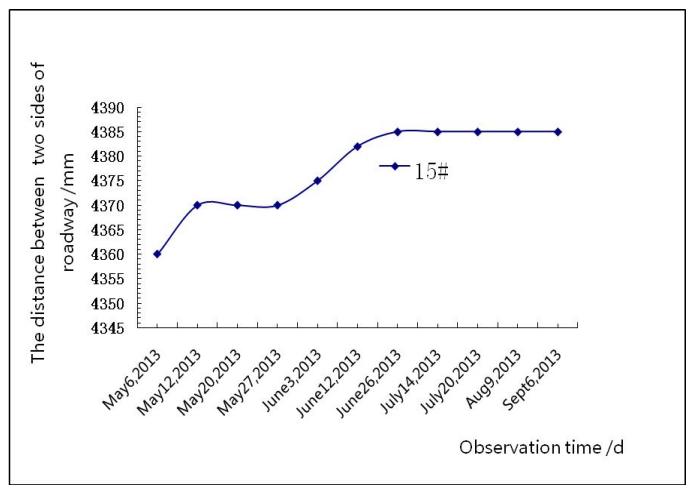

Fig.8 The evolution curve of the distance between two sides of roadway in the 15th observation point

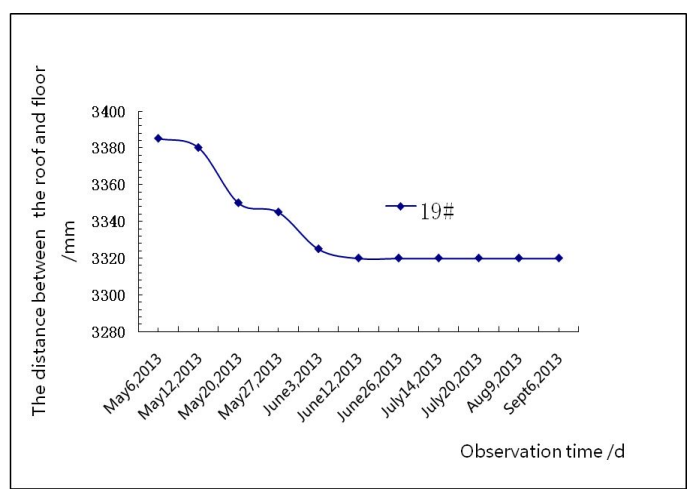

Fig.9 The evolution curve of the distance between roof and floor in the 19th observation point

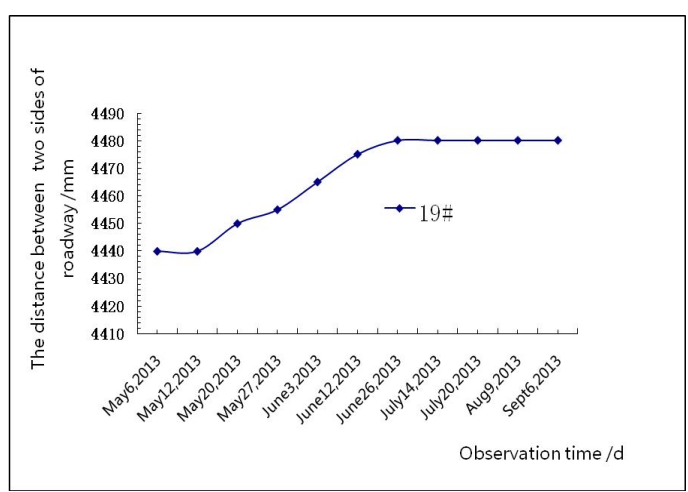

Fig.10 The evolution curve of the distance between two sides of roadway in the 19th observation point

\section{Conclusions}

Through the theoretical research, ANSYS analysis and practice, D-CFST support technology is put forward. Finally , conclusions and future work are summarized:

(1) Compared to circular concrete-filled steel tube, the practice shows that D-CFST has better axial compression and bending resistance. It's bearing capacity also is big. D-CFST support not only provides high load-bearing capacity but also imposes restrictions on the moving of surrounding rock to the roadway space. It can be used as reliable support for roadway in deep mine to ensure the stability of roadway surrounding rock and supporting structure. So D-CFST support structure has a broad application prospect in the future.

(2) Compared to the original U-steel support programs, D-CFST support technology can save a lot of steel, reduce labor intensity and construct rapidly. The measurement of the test shows that D-CFST support program have maintained the stability of the test roadway.

(3) Due to the composite action of steel and its core concrete when forced, concrete-filled steel tube has superior mechanical properties. A combination of different types of core concrete and steel may produce different combinations of effects, so there is a need for a series of experiments to study. But in this paper does not discuss about that, so we can set different combinations of core concrete and steel of the uniaxial compressive strength tests in the future.

\section{References}

[1] CAI Shaohuai, "Modern steel tube confined concrete structures", (revised edition) Beijing: China Communications Press, 2007 (in Chinese) 
[2] HAN Linhai, YANG Youfu, "Modern steel tube confined concrete structures and technology", Beijing: China Architecture and Building Press, 2007 (in Chinese)

[3] ZHONG Shantong, "Steel tube confined concrete structures", Beijing: Tsinghua University Press, 2004 (in Chinese)

[4] Schneider S P, "Axially loaded concrete-filled steel tubes", Journal of Structural Engineering, 1998, 124(10):1125-1138.

[5] ZANG Desheng, "Study on concrete-filled steel tube support" Chinese Journal of Geotechnical Engineering, 2001, 23(3):342-344 (in Chinese)

[6] WANG Qiang, ZANG Desheng, "Experiment and research on mechanics performances of steel pipe concrete support model" Mine construction Technology, 2008, 29(2):33-35 (in Chinese)

[7] GAO Yanfa, WANG Bo, WANG Jun, et al, "Test on structural property and application of concrete-filled steel tube support of deep mine and soft rock roadway", Chinese Journal of Rock Mechanics and Engineering,2010, 29(s1): 2604-2609 (in Chinese)

[8] LI Xuebin, YANG Renshu, GAO Yanfa, et al, "High-strength steel tubular confined concrete supports support technology for large section soft rock inclined shaft", Journal of China Coal Society,2013,38(10):1742-1747 (in Chinese)

[9] CAO Baozhu, ZHANG Yaochun, YU Hongjun, "Experiment and ANSYS finite element analysis on concrete filled thin-walled steel tube joints", Journal of
Jilin Architectural and Civil Engineering Institute, 2007, 24(2):1-4 (in Chinese) [10] LI Yan, ZHAN Meisen, XIONG Jingang, "Experimental research on capacity of concrete-filled thin-walled steel tube under axialcom pression", Concrete, 2008, 11:47-49 (in Chinese)

[11] SU Linwang, ZANG Desheng, "Model experimental study on working performance of concrete filled steel tube support", Chinese Journal of Underground Space and Engineering, 2005, 1(3):992-994 (in Chinese)

[12] SU Linwang, "Experimental research on bearing capacity of curved concrete-filled tubular stub column", Port \&Waterway Engineering, 2010, 446(10):124-129 (in Chinese)

[13] ZHANG Miao, "The optimal design and application research of concrete filled surface heteromorphosis steel tube" Shandong University of Science and Technology, 2013 (in Chinese) 